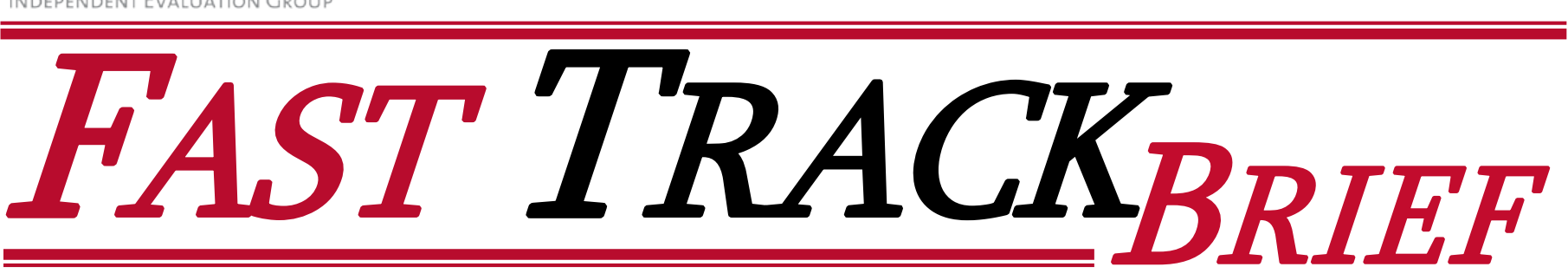

January 28, 2009

The IEG report "Improving Effectiveness and Outcomes for the Poor in Health, Nutrition, and Population," was discussed by CODE on January 28, 2009

\title{
Improving Effectiveness and Outcomes for the Poor in Health, Nutrition, and Population
}

$\checkmark \quad$ The Bank Group now funds a smaller share of global support for health, nutrition, and population (HNP) than it did a decade ago, but its support remains significant $-\$ 17$ billion in countrylevel project financing, in addition to policy advice, analytic work, and engagement in global partnerships by the World Bank and $\$ 873$ million in private health and pharmaceutical investments by IFC from 1997 to mid-2008. The Bank Group continues to play an important role and add value in HNP.

About two-thirds of the Bank's HNP projects show satisfactory outcomes. Performance can be substantially improved by reducing project complexity, strengthening risk assessment and mitigation, conducting more up-front institutional analysis, and incorporating more evaluation to promote evidence-based decisions. The performance of IFC health investments, mainly hospitals, has improved markedly, but IFC has had limited success at diversifying its health portfolio.

The accountability of Bank Group investments for demonstrating results for the poor has been weak. The Bank's investments often have a pro-poor focus, but their objectives need to address the poor explicitly and outcomes among the poor need to be monitored. Importantly, the Bank needs to increase support to reduce high fertility and malnutrition among the poor and ensure discussion of HNP in poverty assessments. IFC-financed hospitals mainly benefit the non-poor; IFC needs to support more activities that both make business sense and yield broader benefits for the poor.

The Bank Group has an important role in helping countries to improve the efficiency of health systems. The Bank needs to better define efficiency objectives, track efficiency outcomes, and support better information and vigorous evaluation of reforms. IFC needs to enhance support to public-private partnerships and improve collaboration and joint sector work with the Bank.

The potential for improving HNP outcomes through actions by non-health sectors is great, but incentives to deliver them are weak. Adding HNP objectives to Bank projects in other sectors, such as water supply and sanitation, raises the incentive to deliver health benefits. Strengthening the complementarity of investments in HNP and other sectors can also improve outcomes. In IFC, incentives, institutional mechanisms, and an integrated approach to health are needed to improve coordination across units. 
ince the late 1990s, when the World Bank Group was

S the largest source of HNP finance to developing countries, new aid donors and institutions have emerged and global HNP development assistance has more than doubled, from an annual average of $\$ 6.7$ billion in 1997/98 to about $\$ 16$ billion in 2006 . The international community has adopted the Millennium Development Goals (MDGs) and other global targets, with a new emphasis on aid effectiveness, results orientation, donor harmonization, alignment, and country leadership, reflected in the 2005 Paris Declaration on Aid Effectiveness and the 2008 Accra Agenda for Action. The World Bank Group, now one of many large players in international HNP support, is reassessing its comparative advantage in the context of the new aid architecture.

World Bank Group support to HNP remains substantial. From 1997 through mid-2008, the World Bank (IBRD and IDA) committed nearly $\$ 17$ billion to $605 \mathrm{HNP}$ projects in more than 120 countries, sponsored analytic work, and offered policy advice. This support aimed to improve health and nutrition status and reduce high fertility; improve the access, quality, efficiency, and equity of the health system; reform health systems through changes in health finance, support for health insurance, decentralization, engaging the private sector, and other structural changes; and strengthen institutional capacity and sector management. In addition, as of 2007 the Bank was engaged financially in 19 global health partnerships and participating in 15 more. IFC has financed 68 private investment projects in the health and pharmaceutical sectors of developing countries_ $\$ 873$ million in total commitments - and offered advisory services on health to the private sector, including support for public-private partnerships.

The World Bank's 2007 strategy, Healthy Development: The World Bank Strategy for Health, Nutrition, and Population Results, aims among other things, to improve HNP outcomes on average and among the poor, prevent poverty due to illness, improve health system performance, and enhance governance, accountability, and transparency in the sector. It points to several strategic directions or actions for the Bank to achieve the objectives, among them: a renewed focus on HNP results; efforts to help countries improve the performance of health systems and to ensure synergy with priority disease interventions, particularly in low-income countries; and strengthened Bank capacity to advise countries on intersectoral approaches to improving HNP results.

The 2002 IFC health strategy defines the sector's goals to improve health outcomes, protect the population from impoverishing effects of ill health, and enhance the performance of health services. The strategy has both business and developmental objectives, including promoting efficiency and innovation in the health sector, and calls for increasing the social impact of IFC investments.

\section{The Scope of the Evaluation}

This evaluation aims to inform the implementation of the World Bank's and IFC's most recent HNP strategies to enhance the effectiveness of future support. It covers the period from FY1997 to FY 2008 and is based on desk reviews of the portfolio, background studies, and field visits. The evaluation of World Bank HNP support focuses on the effectiveness of policy dialogue, analytic work, and lending at the country level, while that of IFC focuses on the performance of health investments and advisory services before and after its 2002 health strategy. The evaluation does not cover the Bank's global partnership engagements in HNP, some of which have been previously evaluated, except to the extent that they are reflected in country-level support. The evaluation benefitted from feedback from an Advisory Panel of international experts.

\section{Bank Support to the Public Sector for HNP}

Over the review period, the World Bank directly supported HNP outcomes in countries through lending and nonlending services. Most lending was from projects managed within the Bank's HNP sector units ( $\$ 11.5$ billion, 255 projects). Beyond this, about $\$ 5$ billion in lending for HNP outcomes was managed by other sectors. Since FY00 the Bank also spent $\$ 43$ million of its own budget and trust funds on HNP-related economic and sector work (ESW). Professional HNP staff grew by a quarter, as did the share of health specialists.

\section{The World Bank's Role}

Although the World Bank finances a smaller share of country-level development assistance under the new international aid architecture, it has an important role and significant potential to add value. The World Bank brings important institutional assets to bear in helping countries make health systems work better and ensuring that health benefits reach the poor: long-term, sustained engagement in the sector; international experience; a history of support for building country capacity to implement programs; large-scale, sustained financing; strong links to finance ministries; and engagement with many sectors other than health with potential to contribute to HNP outcomes. However, the Bank's comparative advantage in a country is context-specific, depending on health conditions, government priorities and resources, and the activities of other development partners. To deliver on its comparative advantages, the Bank needs to improve the performance of its country-level support.

\section{The Evolution and Performance of World Bank Support}

While the overall level of HNP project approvals changed little, the composition of the lending portfolio saw some major shifts. The number of new HNPmanaged projects rose slowly, but new financial commit- 
ments declined. The share of communicable disease projects doubled over the decade, reaching about 40 percent of approvals in the second half of the period, as did the share of multisectoral projects, reaching half of all approvals. The share of Africa region projects also increased. These three trends were due primarily to an increase in multisectoral AIDS projects. Projects supporting sectorwide approaches (SWAps) in health rose to a cumulative total of 28 operations in 22 countries, about 13 percent of the project portfolio. In contrast, the share of lending with objectives to reform the health system dropped by nearly half.

Attention to population and malnutrition was low; support for population nearly disappeared. About 1 in 10 projects had an objective to reduce malnutrition, which disproportionately affects the poor, but the share of projects with nutrition objectives dropped by half over the decade. About two-thirds of nutrition projects were in countries with high levels of child stunting, but Bank nutrition support reached only about a quarter of all developing countries with high stunting. Lending to reduce high fertility or improve access to family planning accounted for only 4 percent of the lending portfolio, dropping by two-thirds over the decade. Population support was directed to only about a quarter of the 35 countries the Bank identified as having fertility rates of more than five children per woman. Analytic work and staffing to support population and family planning objectives nearly disappeared. Substantial analysis of high fertility and malnutrition rarely figured in poverty assessments, though both are most acutely felt by the poor.

Two-thirds of HNP projects had satisfactory outcomes, and the portfolio's performance stalled. Field assessments found that support for reducing malaria in Eritrea and schistosomiasis in Egypt, raising contraceptive use in pilot areas of Malawi, and reforming the health system in the Kyrgyz Republic, for example, showed good results. However, about a third of the HNP lending portfolio did not perform well, a share that has remained steady while performance in other sectors has improved over the decade. Only one in four HNP projects in Africa achieved satisfactory outcomes. Complex projects-multisectoral projects and SWAps-in low-capacity environments were least likely to achieve their objectives. However, health reform projects in middle-income countries also performed less well and are complex and politically volatile. Poorperforming projects displayed common characteristics: inadequate risk analysis or technical design, inadequate supervision, insufficient political or institutional analysis, lack of baseline data on the basis of which to set realistic targets, overly complex designs in relation to local capacity, and negligible monitoring and evaluation (M\&E). These problems are similar to those cited in IEG's 1999 evaluation of the HNP sector. The results of the recent Detailed Implementation Review of HNP projects in India suggest that, even among projects that achieve their objectives, field

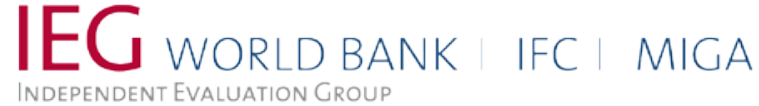

supervision needs to be intensified to ensure that civil works and equipment are delivered as specified, in working order, and functioning.

Accountability of projects for delivering health results to the poor has been weak. Studies of the incidence of public expenditure have shown that in most countries, public health spending favors the non-poor; expansion of services cannot be assumed to improve access of the poor relative to the nonpoor. While many projects targeted HNP support to geographic areas with a high incidence of poverty (including rural areas) or financed services or addressed problems thought to disproportionately affect the poor, only 6 percent of all HNP projects committed to deliver better health or nutrition among the poor in their statement of objectives, for which they were ultimately accountable. A third of projects with objectives to improve general health status had no targeting mechanism for reaching the poor. Among closed projects with objectives to improve HNP outcomes among the poor, most measured a change in average HNP status in project areas. Very few actually measured whether poor individuals or poor project areas benefited in relation to the non-poor or in relation to those in non-project areas, and even fewer showed that the poor did disproportionately benefit. In some cases, improvements in HNP status were only measured at the national level.

The Bank delivered several high-profile analytic products on HNP and poverty in the past decade-notably the Reaching the Poor with Health, Nutrition, and Population Services project and the World Development Report 2004: Making Services Work for Poor People. Nevertheless, the share of country poverty assessments with substantial discussion of health declined, from 80 percent in FY00-03 to only 58 percent in FY04-06. Only 7 percent of poverty assessments had substantial discussion of population, and major discussion of nutrition declined by half, from 28 to 12 percent. About a quarter to a third of Bank HNP analytic work was povertyrelated, also a decline.

An increasing share of projects had monitoring indicators and baseline data at appraisal, but overall monitoring remains weak and evaluation almost nonexistent, presenting a challenge for the HNP strategy's results orientation and commitment to better governance. Although nearly a third of projects supported pilot interventions or programs, or intended to evaluate the impact of a specific activity or program, few proposed evaluation designs in appraisal documents and even fewer evaluations were actually conducted. Pilot activities without an evaluation design described in the appraisal document were never evaluated. There were consequences of poor $\mathrm{M} \& \mathrm{E}$ and absence of baseline data: irrelevant objectives and inappropriate project designs; unrealistic targets - either too high or below the baseline value; inability to assess the effectiveness of activities; and lower efficacy and efficiency because of limited opportunities for learning. 


\section{Approaches for Improving HNP Outcomes}

The evaluation reviewed findings and lessons for a number of prominent approaches to raising HNP outcomescommunicable disease control, health reform, SWAps, and intersectoral action. These approaches have been supported by the Bank and the international community and are not mutually exclusive.

Support for communicable disease control can improve the pro-poor focus of health systems, but excessive earmarking of foreign aid for communicable diseases can distort allocations and reduce capacity in the rest of the health system. One of the strategic directions of the 2007 HNP strategy is to ensure synergy between priority disease interventions and strengthening of the health system. The rationale for investing in infectious diseases is that they disproportionately affect the poor, their control has large positive externalities, and interventions have been shown to be cost-effective in many settings. Dedicated communicable disease projects have dramatically increased as a share of the lending portfolio over the past decade, and Bank support has contributed to country capacity in national disease control programs. Support for control of communicable diseases, with the exception of AIDS, has shown better outcomes than the rest of the HNP portfolio. Both equity and costeffectiveness are particularly important to address in AIDS programs, given the large commitments to that disease and the fact that HIV does not always disproportionately strike the poor.

Since the initial increase in Bank-supported communicable disease control in the early 2000s, mainly for AIDS, the international community has also generously expanded funding through the Global Fund to Fight AIDS, TB, and Malaria and the (U.S.) President's Emergency Plan for AIDS Relief (PEPFAR), other bilateral contributions, and private foundations. In some low-income countries with high HIV prevalence, earmarked AIDS funds from international partners account for 30 or 40 percent or more of all public health funding. Where human resource capacity within the health system is scarce, the allocation of resources across health programs and budget lines needs to be balanced, to ensure that large earmarked funds for specific diseases do not result in lower efficiencies or reduced care elsewhere in the health system. There is little evidence that this issue has been considered in recent funding decisions or in risk analysis.

Health reforms promise to improve efficiency and governance, but they are politically contentious, often complex, and relatively risky. About a third of HNP projects have supported reform or restructuring of the health system through changes in health finance, development of health insurance, decentralization of health systems, and regulation or engagement of the private health sector. These objectives affect efficiency and governance, which are valid objectives in their own right. Health insurance reforms aim to prevent the impoverishing impacts of illness. Bank support for health reforms has been mainly to middle-income countries, where health reform projects represent about half of the portfolio.

Many lessons have been learned over the past decade about the successes and pitfalls of support for health reform. First, the failure to assess fully the political economy of reform and to prepare a proactive plan to address it can considerably diminish prospects for success. Political risks, the interests of key stakeholders, and the risk of complexity are often neglected in risk analysis in project appraisal documents for health reform projects. Second, reforms based on careful prior analytic work hold a greater chance of success, but analytic work does not ensure success. Third, the sequencing of reforms can improve political feasibility, reduce complexity, ensure that adequate capacity is in place, and facilitate learning. When implementation is flagging, the Bank can help preserve reform momentum with complementary programmatic lending, as it did in Peru and Kyrgyz Republic. Finally, $\mathrm{M} \& \mathrm{E}$ are critical in health reform projects-to demonstrate the impact of pilot reforms for garnering political support but also because many reforms cannot work without a wellfunctioning information system.

SWAps have contributed to greater government leadership, capacity, coordination, and harmonization within the health sector, but not necessarily to improved efficiency or better health results. Sectorwide approaches represent a reform in the way that government and international donors work together (the approach) to support the achievement of national health objectives (the program). The overwhelming focus of SWAps supported by the Bank has been on setting up and implementing the approach. Fieldwork found that country capacity has been strengthened in the areas of sector planning, budgeting, and fiduciary systems. However, weaknesses persist in the design and use of country M\&E systems; evidence that the approach has improved efficiency or lowered transaction costs is thin because neither has been monitored.

Adopting the approach does not necessarily lead to better implementation or efficacy of the government's health programs: only a third of Bank projects that supported health SWAps have had satisfactory outcomes. SWAps have often supported ambitious programs with many complex reforms and activities that exceed government implementation capacity. Important lessons are that programs need to be realistic and prioritized and that the process of setting up the SWAp should not distract from ensuring the implementation and efficacy of the overall health program and a focus on results. SWAps have been most effective in pursuing health program objectives when the government is in a leadership position with a strongly owned and prioritized strategy (as in the Kyrgyz Republic). When this is not the case, there is a risk that the health program will be less prioritized reflecting the fa- 
vored elements of the diverse partners, weakening effectiveness (as in Ghana).

The contribution of other sectors to HNP outcomes has been largely undocumented; the benefits of intersectoral coordination and multisectoral approaches need to be balanced with their costs in terms of increased complexity. The contribution of other sectors to HNP outcomes has been captured through multisectoral HNP projects (projects that engage multiple sectors in a single operation) and parallel lending in projects managed by other sectors, in some cases with explicit health objectives. Multisectoral HNP operations have risen from a quarter to half of HNP lending, increasing the complexity of the portfolio. Most of the increase is due to multisectoral AIDS projects. The large number of sectors involved, the lack of specificity in design documents about their roles and responsibilities, the relatively new institutions put in charge, and other factors affecting lower performance in Africa all contribute to lower outcomes for multisectoral AIDS projects. Multisectoral HNP projects with fewer implementing agencies have maintained stronger intersectoral collaboration and better outcomes.

Both the 2007 HNP strategy and its predecessor foresaw Country Assistance Strategies as the instrument to coordinate intersectoral action for HNP outcomes. However, over the past decade lending in diverse sectors like water supply and sanitation (WSS) and education for the most part has been pursued independently, although this does not mean that they have not contributed to health outcomes.

Lending in other sectors may contribute directly to HNP outcomes, in some cases by including health objectives or health components, or indirectly. For example, half of all WSS projects claim that health benefits will be generated, and one in 10 has an objective to improve health outcomes. However, fewer WSS projects include health objectives today than was the case 5-10 years ago. Interviews with staff suggested that the sector has focused primarily on what is perceived to be "their" MDG, namely increased access to safe water. Yet research has shown that context matters; better access to safe water does not necessarily translate into better health. In contrast, the health content of transport projects has greatly increased, particularly in the field of road safety and HIV/AIDS prevention. Trends in accident statistics have been relatively well documented for road safety components; the outputs and results for HIV/AIDS components have not. Delivery of health results in non-health sectors has been generally weak except when an explicit health objective was identified at project appraisal.

\section{IFC Support for Development of the Private Health Sector}

IFC has made support to private health investment one of its strategic priorities. Health is a relatively small and recent sec-

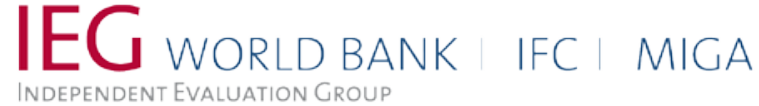

tor at IFC, involving both the Health and Education and General Manufacturing departments (for pharmaceuticals).

The performance of IFC's health investments, mostly hospitals, improved substantially. Before 1999, four-fifths of all health investments performed poorly, contributing to financial losses. The reasons included the impact of financial crises, delays in obtaining regulatory clearances from the authorities, and IFC's weaknesses in screening and structuring health sector deals owning to lack of sector-related experience. More recent investments have realized good financial returns and performed better on achieving intended development outcomes. An evaluative framework for IFC's Advisory Services was only recently launched, so very few health Advisory Services projects have been evaluated. However, the few that have been evaluated have performed lower than the IFC portfolio overall.

IFC has not been able to diversify its health portfolio as envisaged. In 2002, the sector set objectives to diversify the portfolio beyond hospitals and improve the social impact of IFC health operations. IFC has continued to finance private hospitals; the share of pharmaceuticals and other life sciences investments has grown, but more slowly than envisioned in the strategy. IFC has also financed public-private partnerships (PPPs) in health and expanded health Advisory Services with a focus on Africa. Investment numbers and volume have increased since 2005. However, IFC has not financed any health insurance ventures and has financed only one project on medical education.

IFC's health interventions have had limited social impact, although efforts are being made to broaden those impacts. IFC's investments in hospitals have targeted middle- and upper-income groups. Linkages to public insurance schemes will be necessary for IFC-supported hospitals to meet the health needs of a wider population. Expanded support to PPPs jointly with the World Bank, such as a recent output-based aid project to improve maternal care among some of Yemen's poorest people, and more strategic deployment of Advisory Services, such as to assist social enterprises in Kenya and India, could help broaden the social impact of health investments.

Recent IFC health projects have had positive results for efficiency, governance, and affordability. State-of-the-art facilities in some IFC-supported projects have attracted professionals with established successful careers in developed countries. Many hospitals supported by IFC have posted fees and introduced control of doctors' side practices outside of the institutions. Most IFC-supported pharmaceutical projects have resulted in significant declines in the prices of generic drugs, thus enhancing affordability.

The need to collaborate closely with the World Bank's HNP sector is recognized as important in both IFC and World Bank strategies to promote greater efficiency in the health 
sector through finance of private health care. The evaluation found some interaction, particularly in middle-income countries, but there is no real model of how that collaboration should occur in a situation where IFC health activities are few and very small in relation to the entire World Bank Group HNP sector in a country.

\section{Recommendations}

- Intensify efforts to improve the performance of the World Bank's health, nutrition, and population support. This calls for matching project design to country context and capacity and reducing the complexity of projects in low-capacity settings, through greater selectivity, prioritization, and sequencing of activities; carefully assessing the risks of proposed HNP support and strategies to mitigate them, particularly the political risks and the interests of different stakeholders, and how they will be addressed; phasing reforms to maximize the probability of success; undertaking thorough institutional analysis, including an assessment of alternatives, as an input into more realistic project design; and supporting intensified supervision in the field by the Bank and the borrower to ensure that civil works, equipment, and other outputs have been delivered as specified, are functioning, and being maintained.

- Renew the commitment to health, nutrition, and population outcomes among the poor. For the $W$ orld Bank, this means boosting population, family planning, and other support in the form of analytic work, policy dialogue, and financing to high fertility countries and countries with pockets of high fertility; incorporating the poverty dimension into project objectives to increase accountability for health, nutrition, and population outcomes among the poor; increasing support to reduce malnutrition among the poor, whether originating in the HNP sector or other sectors; monitoring health, nutrition, and population outcomes among the poor, however defined; and bringing the health and nutrition of the poor and the links between high fertility, poor health, and poverty back into poverty assessments. For IFC, this means expanding support for innovative approaches and viable business models that demonstrate private sector solutions to improve the health of the poor, including expansion of investments in low-cost generic drugs and technologies that address health problems of the poor; and assessing the external and internal constraints in achieving broad social impacts.

- Strengthen the World Bank Group's ability to help countries improve the efficiency of health systems. For the World Bank this means better defining the efficiency objectives of its support and how efficiency will be improved and monitored; carefully assessing decisions to finance additional earmarked communicable disease activities in countries where other donors are contributing large amounts of earmarked disease funding and additional earmarked funding could result in distortions in allocations and inefficiencies in the rest of the health system; and supporting improved health information systems and more frequent and vigorous evaluation of specific reforms or program innovations to provide timely information for improving efficiency and efficacy. For IFC this means supporting PPPs through Advisory Services to government and industry and through its investments; expanding investments in health insurance; and improving collaboration and joint sector work with the World Bank, leveraging Bank sector dialogue on health regulatory frameworks for health to engage new private actors with value added to the sector, and more systematically coordinate with the Bank's policy interventions regarding private sector participation in health.

- Enhance the contribution of support from other sectors to health, nutrition, and population outcomes. The World Bank needs to incorporate health objectives for which they are accountable into non-health projects when the benefits are potentially great in relation to the marginal costs; improve the complementarity of investment operations in health and other sectors to achieve HNP outcomes, particularly between health and WSS; prioritize sectoral participation in multisectoral HNP projects according to the comparative advantages and institutional mandates, to reduce their complexity; identify new incentives for Bank staff to work crosssectorally for improving HNP outcomes; and develop mechanisms to ensure that the implementation and results for small HNP components retrofitted into projects are properly documented and evaluated. IFC should improve incentives and institutional mechanisms for an integrated approach to health issues across units in IFC dealing with health, including the way IFC is organized.

- Implement the results agenda and improve governance by boosting investment in and incentives for evaluation. The $W$ orld Bank needs to create new incentives for M\&E for both the Bank and the borrower linked to the project approval process and the midterm review. This would include requirements for baseline data, explicit evaluation designs for pilot activities in project appraisal documents, and periodic evaluation of main project activities as a management tool. IFC needs to enhance its results orientation by developing clearly specified baseline indicators and an evaluation framework that adequately measure its health sector objectives and results. 


\begin{abstract}
About Fast Track Briefs
Fast Track Briefs help inform the World Bank Group (WBG) managers and staff about new evaluation findings and recommendations. The views expressed here are those of IEG and should not be attributed to the WBG or its affiliated organizations. Management's Response to IEG is included in the published IEG report. The findings here do not support any general inferences beyond the scope of the evaluation, including any inferences about the WBG's past, current or prospective overall performance.

***

The Fast Track Brief, which summarizes major IEG evaluations, will be distributed to World Bank Group staff. If you would like to be added to the subscription list, please email us at ieg@worldbank.org,with "FTB subscription" in the subject line and your mail-stop number. If you would like to stop receiving FTBs, please email us at ieg@worldbank.org,with "FTB unsubscribe" in the subject line.
\end{abstract}

\title{
Contact IEG:
}

Director-General, Evaluation: Vinod Thomas

Directors: Marvin Taylor-Dormond (IEG-IFC)

Christine Wallich (IEG-MIGA)

Cheryl Gray (IEG-WB)

Task Managers: Stoyan Tenev (IEG-IFC)

Hiroyuki Hatashima (IEG-IFC)

Martha Ainsworth (IEG-WB)

Copies of the report are available at:

http://www.worldbank.org/ieg/hnp

IEG Help Desk: (202) 458-4497

E-mail: ieg@worldbank.org 